\title{
Heat Transfer Simulation for Nano-Coated Glass in Saudi Arabia
}

\author{
Ahmed Almogbel ${ }^{1, a}$, Saleh Alajlan ${ }^{1}$ and Shafqat Hussain ${ }^{2}$
}

\begin{abstract}
The amount of heat flow within building interior is important for understanding and predicting its thermal behaviors. To achieve greater energy efficiency of a building, the performance of window system is required to improve. Glazing materials in windows provide adequate illumination levels in the interior of buildings receiving the visible part of solar radiation. The other part of solar radiation in the infrared region entering through glazing causes increase of interior temperature. Hence glazing is a major component in designing and analyzing problems such as energy demands, assessment of heating and cooling loads and thermal comfort in a building. This study focuses on the thermal behavior of glass for development of functional nano-coatings of window glazing for the regional conditions in Saudi-Arabia. Different materials and its optimized film properties of thickness and doping level of antimony tin oxides (ATO) were prepared and their optical and thermal properties were systematically investigated. Glass U-factor, Solar Heat Gain Coefficient (SHGC) and net heat transfer through window were calculated. The results showed that the thermal insulation of the glass effect of coating thickness and doping level was significant. The simulated net heat transfer through window decreased linearly with increase of both of coating thickness or ATO concentration. Furthermore, the overall transmittance in the visible region and reflectance in infrared and ultraviolent regions decrease with increasing of weight content of antimony doped tin oxides ATO, and similarly for increasing of coating thickness.
\end{abstract}

Keywords - Nano Coating, Simulation, Heat Transfer.

\section{INTRODUCTION}

In hot climates, the excess of solar radiation penetrating through windows increases cooling loads. The cooling load in hot climates can be reduced by adopting passive mechanisms to minimize the solar heat gain through glass windows which reduce the direct solar radiation entering the buildings without reducing the natural illumination. However, in cold climates, it is necessary to increase the fraction of solar radiation entering the buildings without causing any condensation [1]. Thus, the improvement of the window system is a very attractive area of research to develop energy-efficient buildings. In addition, the proper selection of glazing material can reduce the solar heat gain component in summer as also heat loss in winter [2]

The amount of energy consumed through heating, cooling or lighting in a building is mostly affected by its fenestration system which provides a view, light and fresh air to the building. The study of the heat flow through the building

${ }^{1}$ Water and Energy Research Institute, King Abdulaziz City of Science and Technology, P.O.Box 6086 Riyadh 11442, Saudi Arabia

${ }^{2}$ Al Imam Mohammad Ibn Saud Islamic University, Riyadh Saudi Arabia fenestrations is important for understanding and predicting its thermal behaviors. The thermal energy flows through fenestration is transferred via conductive, convective and radiation modes of heat transfer, which caused by the temperature difference between outdoor and indoor air, the net long-wave (above $2500 \mathrm{~nm}$ ) radiative exchange between the fenestration and its surroundings and the short-wave (below $2500 \mathrm{~nm}$ ) solar radiation incident on the fenestration product, either directly from the sun or reflected from the ground or adjacent objects [3]. In general, the overall heat transfer coefficient (or U-value) of windows is five times greater than those of other components of a building's envelope (e.g., walls, doors, etc.), and about $20-40 \%$ of energy in a building is wasted through windows [4]. The solar radiation incident over the external surface is partially reflected, transmitted and absorbed by the glass sheet. The portion absorbed increases the internal energy of the glass sheet and hence its temperature also increases. Additionally the glass window loses or gains heat from the internal and external ambient by conduction, convection and long wave radiation.

Since the building sector is a major consumer of energy, many studies have been conducted into the effect on building energy load reduction. A new analytical method based on one dimensional heat conduction is presented in [5], which provides a close-formed solution for both transient indoor and envelope temperature changes in buildings and obtained an approximate analytical solution for heat transfer. While numerical simulations of heat transfer by natural convection in cavities of facade elements is studied in [6], which focused on overall convection heat flow through the air layer. To evaluate the whole building performance, a mathematical model applied to the analysis of hydrothermal behavior of buildings is presented in [7]. A study [8] was carried out in Hong Kong to describe the influence of the building envelope construction on the space cooling loads in residential buildings. It is found that the solar heat gain through the fenestration systems is a major component of building energy performance and residents comfort and summer cooling loads in buildings can be reduced significantly with windows of low solar heat gain coefficients (SHGC). 


\section{SimULATIONS}

Thermal parameters like the U-value and solar heat gain coefficient (SHGC) of different types of coated glass were calculated using the WINDOW 7.2 software (Lawrence Berkeley National Laboratory (LBNL)) [9]. This software uses the solar transmission and reflection data obtained from the spectrophotometric measurements. To predict the net heat transfer gains, a test room was considered with glazed walls of different nano-coatings and simulations were performed using commercial CFD software, ANSYSIS FLUENT.

\section{A. Test Room Design Configuration}

For this study a glazed room $(8 \times 5 \times 4 \mathrm{~m})$ of volume $160 \mathrm{~m} 3$ was simulated as a test case to study the net heat transfer and temperature distribution within the room. The basic design configuration of a room considered is shown in Fig.1. All walls of the room were assumed to be made of different types of nanomaterial-coated glass and roof/floor surfaces are assumed to be made of concrete.

Optical and thermal properties of nanomaterial-coated glazing used in the construction of the walls of the room are given in Table 1a and Table 1b. In order to utilize the CFD model from the previous studies [10,11], the simulated room was assumed to be located and oriented 0 degree with Longitude (deg) 46.77 and Latitude 24.64 (deg), facing southward in the region of Riyadh city in Saudi Arabia. The room was fully closed to observe the effect of optical properties of glass coatings on net heat transfer gain within the room. Thermal properties of the materials assumed in the envelop of the room are given in Table 1.

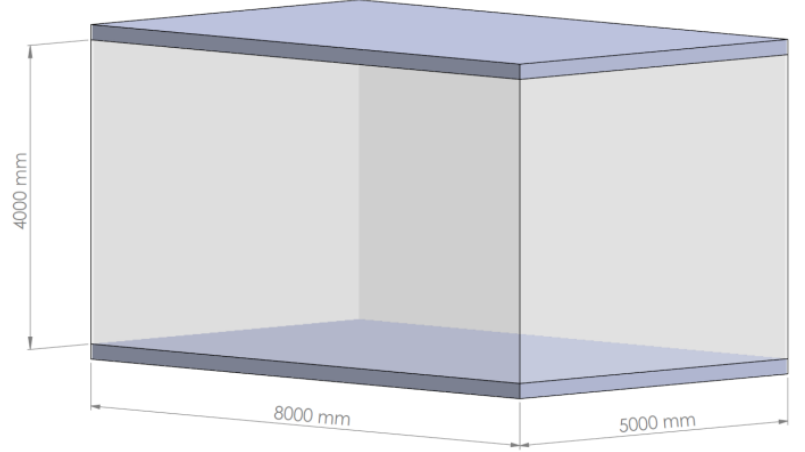

Fig.1: Basic design configuration of the considered room

TABLE 1: THERMAL Properties OF THE MATERIALS USED IN THE ENVELOP OF THE ROOM

Thermal Properties

\begin{tabular}{c|c|c|c}
\hline Materials & $\begin{array}{c}\text { Density } \\
\left(\mathrm{kg} / \mathrm{m}^{3}\right)\end{array}$ & $\begin{array}{c}\text { Thermal } \\
\text { conductivity } \\
(\mathrm{W} /(\mathrm{m} \cdot \mathrm{K}))\end{array}$ & $\begin{array}{c}\text { Specific Heat } \\
\left(\mathrm{J} / \mathrm{kg}{ }^{\circ} \mathrm{C}\right)\end{array}$ \\
\hline Concrete & 2400 & 1.28 & 880 \\
\hline Coated Glazing & 2225 & 1.4 & 835 \\
\hline \hline
\end{tabular}

\section{B. Numerical Solution Procedures}

The airflow patterns and temperature distributions in the office room are governed by the conservation laws of mass, momentum and energy. The mathematical model applied includes the numerical techniques to solve the continuity, Navier-Stokes (N-S), and energy equations for 3D, turbulent flow. In order to recognize the potential time-averaged value of temperatures and velocities, the solution was obtained using the Reynolds averaged governing equations for steady, incompressible, three-dimensional and turbulent flow. In dealing with the buoyancy forces in the momentum equations the Boussinesq approach was adopted, i.e., it was assumed that the fluid properties are constant except for the density change with temperature which gives rise to the buoyancy forces, these being dealt with a linear relation between the density change and the temperature change. In addition, the dissipation term in the energy equation was neglected due to the low velocities involved. As noted from our previous studies [10-11] for the evaluation of turbulence models and from literature survey, the SST-kw turbulence model along with a radiation model DTRM was considered suitable for present CFD simulations. The resultant steady-state governing equations were solved using the commercial CFD solver FLUENT. Pressure coupling as treated using the SIMPLE algorithm. The second-order upwind scheme was used to discretize the momentum, turbulent kinetic energy, dissipation rate and energy conservation equations. The body force weighted scheme was used to discretize pressure velocity coupling. These were solved in a segregated manner. Convergence was considered to have been reached when the energy residual was less than $0.01 \%$ and the flow variables residuals varied by $0.1 \%$ over the last 100 iterations. The under relaxation factors for pressure, density, momentum, turbulence kinetic energy, turbulence dissipation rate, turbulent viscosity, energy $0.3,1,2,0.8,0.8,1,0.9$ respectively were used to get the solution converged.

\section{RESULTS AND DISCUSSION}

A Nano-Coating glazing of ATO was deposited on different glass substrates at temperature $500 \mathrm{oC}$ according to the aerosol-assisted chemical vapor deposition (AACVD) procedures. Variation of the antimony concentration $(0,5,10$, $15 \%)$ and the ATO coating film thickness $(228,456,570,912$, $1140 \mathrm{~nm}$ ) were considered in this study. The thermal properties of the thin films, SHGC and U-value were calculated using the WINDOW 7.2 software program. The results with samples of glazing at different antimony oxides doping level (\%) in the form of measured optical properties and calculated thermal properties are listed in Table 2 whereas the results for thin film coatings with different film thicknesses in the form of measured optical properties and calculated thermal properties are listed in Table 3. 
TABLE 2: OpticAl \& THERMAL Properties For Thin Film CoATINGS WITH DIFFERENT ANTIMONY DOPING LEVEL

\begin{tabular}{c|c|c|c|c|c}
\hline \hline $\begin{array}{c}\text { Sample at } \\
\begin{array}{c}\text { Different Doping } \\
\text { Level (\%) }\end{array}\end{array}$ & TVIS & TIR & $\begin{array}{c}\mathrm{U} \\
\left(\mathrm{W} / \mathrm{m}^{2}\right. \\
\left.{ }^{0} \mathrm{C}\right)\end{array}$ & SHGC & $\begin{array}{c}\text { Net Heat Gain } \\
(\mathrm{W})\end{array}$ \\
\hline 0 & 0.742 & 0.718 & 3.45 & 0.657 & 587.95 \\
\hline 5 & 0.693 & 0.308 & 3.35 & 0.614 & 547.05 \\
\hline 10 & 0.647 & 0.232 & 3.3 & 0.559 & 493.3 \\
\hline 15 & 0.432 & 0.114 & 2.65 & 0.364 & 311.94 \\
\hline \hline
\end{tabular}

TABLE 3: OPTICAL \& THERMAL PROPERTIES FOR THIN FILM COATINGS WITH DIFFERENT FILM THICKNESS

\begin{tabular}{c|c|c|c|c|c}
\hline \hline $\begin{array}{c}\text { Sample at } \\
\text { Different Doping } \\
\text { Level (\%) }\end{array}$ & TVIS & TIR & $\begin{array}{c}\text { U } \\
\left(\mathrm{W} / \mathrm{m}^{2}\right. \\
0\end{array}$ & SHGC & $\begin{array}{c}\text { Net Heat } \\
\text { Gain } \\
(\mathrm{W})\end{array}$ \\
\hline 0 & 0.881 & 0.817 & 5.8 & 0.72 & 827.75 \\
\hline 228 & 0.614 & 0.383 & 3.25 & 0.545 & 480.03 \\
\hline 456 & 0.439 & 0.199 & 3.1 & 0.387 & 325.54 \\
\hline 570 & 0.395 & 0.90 & 2.55 & 0.362 & 311.79 \\
\hline 912 & 0.153 & 0.024 & 2.75 & 0.157 & 102.22 \\
\hline 1140 & 0.114 & 0.012 & 2.45 & 0.122 & 73.21 \\
\hline \hline
\end{tabular}

From the data listed in Table 2 it will be seen that the antimony doping level of the tin oxide thin films has significant effect on the SHGC values with slight variation in the U-factor. The variation in SHGC values with different antimony doping level is shown in Fig.2. It is observed that an increase in the antimony doping level results in a decrease of SHGF values exponentially which indicates that lower value of the SHGC leads to less solar heat gain through glazed walls, which has a positive effect in the energy saving for HVAC loads. Similarly from the data listed in table 3 it is found that coating film thickness also has significant effect on the SHGC values. The variation in SHGC values with different thin film thickness is illustrated in Fig. 3 which shows that an increase in the coating film thickness results in decrease of SHGF values which means a higher thin film thickness at certain level gives a good impact on energy consumption in buildings.

A series of CFD simulations were run to obtain results for the atmospheric conditions at 13:00 $\mathrm{h}$ on 15 th June with an ambient temperature of $45 \mathrm{oC}$ and a relative humidity of $15 \%$ in the region of Riyadh, Saudi Arabia. For the different nanocoatings optical properties, net heat gains were calculated through glazed walls in response to each coating considered. The floor and ceiling of the room were assumed adiabatic. The effect of two main variables of nano-coatings, namely the doping level of antimony and thin film thickness were considered in the present simulations.

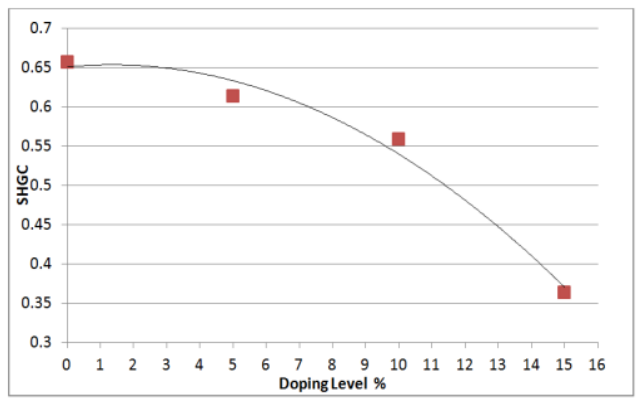

Fig. 2: SHGC with different antimony doping level

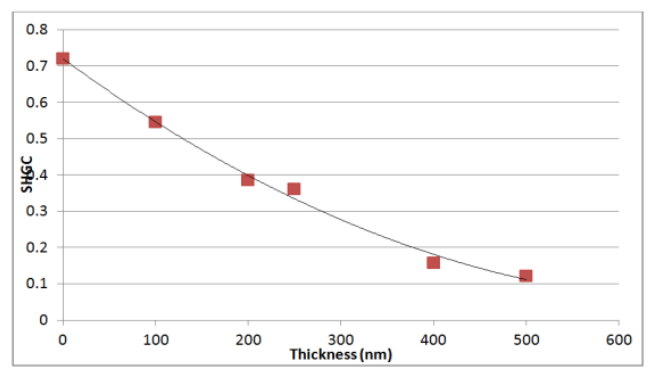

Fig. 3:. SHGC with different thin film thickness

The effect of different doping level of antimony oxides on the net heat gain inside the room is shown in Fig. 4. From the Fig. 4 it can be seen that with the increase of doping level of antimony, the net heat gain values decease exponentially. The increase of doping concentration has a positive effect on the heat transfer rates and causes decrease in the inside temperature values. The intensity of the solar heat flux is the motive force to assess the thermal load and is thus the most determinant factor for the assessment of the energy performance of any building.

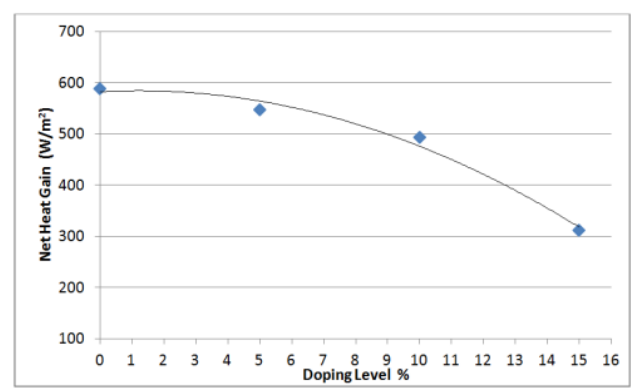

Fig. 4: Net heat gain with different doping level

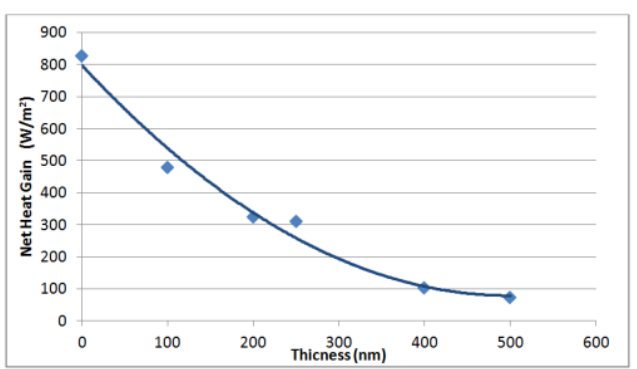

Fig. 5: Net heat gain with different thin film thickness 
The net heat gain was found to rise with the increase in solar heat flux. The glazing type and optical properties affects the heat transfer and corresponding changes in the temperature distributions in the building. Similarly the net heat gain through the glazed walls of the room was calculated for the different values of the thin film thickness and the effect of thin film thickness on the net heat gain inside the room is shown in Fig.5.

\section{CONCLUSIONS}

This study was undertaken to investigate the thermal behaviour of glass for development of functional nanocoatings of glazed walls in a test room for the regional conditions of Saudi-Arabia. Different glass coatings and their optimized film properties of thickness and doping level of antimony tin oxides (ATO) were prepared and their optical and thermal properties were systematically investigated. Glass U-factor, Solar Heat Gain Coefficient (SHGC) and net heat transfer through glazed walls were calculated using the WINDOW software and CFD commercial software ANYSISFLUENT. The results showed that the effect of coating thickness and doping level (\%) on the thermal insulation of the glass was significant. The net heat transfer gain through glazed walls was calculated using CFD simulations. From the numerical results it was concluded that net heat transfer gain inside the room decreased exponentially with the increase of coating thickness or ATO concentration. Furthermore, the overall transmittance in the visible region and reflectance in infrared and ultraviolent regions decrease with increasing of weight content of antimony doped tin oxides ATO, and increasing of coating thickness.

\section{V.ACKNOWLEDGEMENT}

This research work is supported by Water and Energy Institute at King Abdulaziz City for Science and Technology (KACST), Riyadh, Saudi Arabia. The authors would like to acknowledge Saudi American Glass Company for their support and cooperation.

\section{REFERENCES}

[1] K.A.R. Ismail, J.R. Henríquez, "Modeling and simulation of a simple glass window", Solar Energy Materials and Solar Cells, Volume 80, Issue 3, November 2003, Pages 355-374, ISSN 0927-0248, http://dx.doi.org/10.1016/j.solmat.2003.08.010.

[2] Sujoy Pal, Biswanath Roy, "Subhasis Neogi, Heat transfer modelling on windows and glazing under the exposure of solar radiation", Energy and Buildings, Volume 41, Issue 6, June 2009, Pages 654-661, ISSN 0378-7788, http://dx.doi.org/10.1016/j.enbuild.2009.01.003.

[3] American Society of Heating, Refrigeration and Air-conditioning Engineers (1997), ASHRAE Handbook of fundamentals (SI edition).

[4] J.W. Lee, H.J. Jung, J.Y. Park, J.B. Lee, Y. Yoon, "Optimization of building window system in Asian regions by analyzing solar heat gain and daylighting elements", Renewable Energy, Volume 50, February 2013, Pages 522-531, ISSN 0960-1481

http://dx.doi.org/10.1016/j.renene.2012.07.029.

[5] X. Lü, T. Lu, M. Viljanen, "A new analytical method to simulate heat transfer process in buildings", Applied Thermal Engineering, Volume 26, Issue 16, November 2006, Pages 1901-1909, ISSN1359-4311, http://dx.doi.org/10.1016/j.applthermaleng.2006.01.017.

[6] Heinrich Manz, "Numerical simulation of heat transfer by natural convection in cavities of facade elements", Energy and Buildings, Volume 35, Issue 3, March 2003, Pages 305-311, ISSN 0378-7788, http://dx.doi.org/10.1016/S0378-7788(02)00088-9.

[7] Gerson H. dos Santos, Nathan Mendes, "Analysis of numerical methods and simulation time step effects on the prediction of building thermal performance", Applied Thermal Engineering, Volume 24, Issues 8-9, June 2004, Pages 1129-1142, ISSN1359-4311, http://dx.doi.org/10.1016/j.applthermaleng.2003.11.029.

[8] M Bojic, F Yik, K Wan, J Burnett, "Influence of envelope and partition characteristics on the space cooling of high-rise residential buildings in Hong Kong", Building and Environment, Volume 37, Issue 4, April 2002, Pages 347-355, ISSN 0360-1323, http://dx.doi.org/10.1016/S0360-1323(01)00045-2.

[9] http://windows.lbl.gov/software/NFRC/SimMan/NFRCSim6.3-2013-07Manual.pdf

[10] S. Hussain, P.H. Oosthuizen, "An evaluation of turbulence models for the numerical study of flow and temperature distribution in atria", in: 18th Annual Conference of the CFD Society of Canada, London Ontario, 17e19 May 2010.

[11] S. Hussain, P.H. Oosthuizen, "Validation of numerical study of flow and temperature distribution in an atrium space", in: 19th Annual Conference of the CFD Society of Canada Montreal, Canada, 27e29 April 2011. 